УДК 316.6

$10.17213 / 2075-2067-2020-6-69-80$

\title{
СОЦИАЛЬНАЯ СПЛОЧЕННОСТЬ МИГРАНТОВ: ПРОЯВЛЕНИЕ В СОЦИАЛЬНЫХ СЕТЯХ В УСЛОВИЯХ ГЛОБАЛЬНЫХ СОЦИАЛЬНЫХ ИЗМЕНЕНИЙ
}

\author{
(С) 2020 г. В. И. Курбатов, Ю. Г. Волков \\ Южнн-Российский филиал Федерального научно-исследовательского \\ социологического центра РАН, г. Ростов-на-Дону, Россия
}

\begin{abstract}
Цель исследования - выявление и анализ факторов и тенденичий становления и развития сочиальной сплоченности мигрантов.

Методологической базой исследования являются системные методы оценки сообщений в мигрантских соџиальных сетях, становящихся мигрантскими социальными медиа, методы сетевого анализа, методы масс-медийных практик и мигрантской риторики в публичных материалах, посредством выделения, сравнения, оценки и концептуализачии тенденциий трансформации миграционных проиессов под действием глобальных изменений, в том числе и вызванных пандемией COVID-19, а также методы дискурсивного анализа мигрантского дискурса, представленного в аналитических материала.
\end{abstract}

Результаты исследования. В данной статье обсуждается сочиильная сплоченность мигрантов, формирующаяся как дополнение этнической сплоченности в результате понижения уровня доверия у мигрантов к принимающему обществу и государству в условиях глобальных сочиальных изменений, в том числе и в условиях пандемии COVID-19. Мигрантыл, оказавшиеся в данной ситуации наименее защищенной социальной стратой, формируют межэтническую социальную сплоченность как форму самоорганизации этнических общин в кризисное время. Социальная сплоченность мигрантов находит свое отражение в масс-медийных практиках, в сетевом информационном взаимодействии и в научных аналитических материалах, в которых оцениваются факторы, выступающие триггерами новых тенденций в миграционном прочессе: рост ксенофобных, мигрантофобных и расистских настроений у части населения принимающих стран, ограничение мобильности международных мигрантов, обострение конкуренции мигрантов с коренным населением за рабочие места. К числу новых тенденций миграционного процесса следует отнести усиление транснациональных умонастроений и действий мигрантов, которое выражается в массовых движениях протестной, правозащитной и гуманитарной направленности, а также в массовом перемещчении соичиальных связей и отношений мигрантов из сферы «офрф-лайн» сферу «он-лайн», в область сочииальных сетей, в циифровые эмигрантские диаспоры, в сферу циирровых масс-медийных практик.

Перспектива исследования. Данные тренды, хотя они имеют неоднозначный характер, в будущем могут стать основой миграционной политики национальных государств и предметом сочиологических исследований.

Ключевые слова: мигранты; миграционные прочессы; пандемия; мигрантская риторика; мигрантский дискурс; ксенофобия; мигрантофобия; расизм; мобильность мигрантов; транснациональность; миграционная политика начиональных государств. 


\title{
SOCIAL COHESION OF MIGRANTS: MANIFESTATION IN SOCIAL NETWORKS IN THE CONTEXT OF GLOBAL SOCIAL CHANGES
}

\author{
(C) 2020 V. I. Kurbatov, Yu. G. Volkov
}

\author{
South-Russian branch of the Federal Research Sociological Center \\ of the Russian Academy of Sciences, Rostov-on-Don, Russia
}

The purpose of the research is to identify and analyze the factors and trends in the formation and development of social cohesion of migrants.

The methodological basis of the research is system methods for evaluating messages in migrant social networks that are becoming migrant social media, methods of network analysis, methods of mass media practices and migrant rhetoric in public materials, by highlighting, comparing, evaluating and conceptualizing trends in the transformation of migration processes under the influence of global changes, including those caused by the COVID-19 pandemic, as well as methods of discursive analysis of migrant discourse presented in analytical materials.

Research results. This article discusses the social cohesion of migrants, which is formed as an addition to ethnic cohesion as a result of a decrease in the level of trust among migrants in the host society and state in the context of global social changes, including in the context of the COVID-19 pandemic. Migrants who find themselves in this situation the least protected social strata form inter-ethnic social cohesion as a form of self-organization of ethnic communities in times of crisis. The social cohesion of migrants is reflected in mass media practices, online information interaction, and scientific analytical materials that assess factors that trigger new trends in the migration process, such as the growth of xenophobic, migrant-phobic, and racist attitudes among a part of the population of host countries, restrictions on the mobility of international migrants, and increased competition between migrants and the indigenous population for jobs. Among the new trends in the migration process should be attributed the strengthening of transnational attitudes and actions of migrants, which are expressed in mass protest, human rights and humanitarian movements, as well as in the massive movement of social connections and relations of migrants from the "offline» to the "online» sphere, to the social networks, into the digital emigrant diasporas, into the sphere of digital mass media practices.

Research perspective. These trends, although they are ambiguous, may become the basis of migration policy of national States and the subject of sociological research in the future.

Key words: migrants; migration processes; pandemic; migrant rhetoric; migrant discourse; xenophobia migrant phobia; racism; migrant mobility; transnationality; migration policy of national states.

Актуальность исследования. Социальная сплоченность мигрантов есть множество вертикальных и горизонтальных взаимодействий между членами мигрантского сообщества, которое включает в себя совокупность установок и норм, основанных на чувстве принадлежности к социуму сообщества, на доверии и готовности участвовать в делах сообщества, на отношении к другим сообществам и к принимающему обществу в целом.

Она имеет прямое отношение к таким базовым параметрам международных миграционных процессов, как этническая солидарность, этнический и социальный капитал, идентичность мигрантов. Изменение указанных параметров существенным образом конституирует и трансформирует понятие социальной сплоченности. 
В настоящее время в условиях глобальных изменений, в частности, пандемии COVID-19, охватившей всю планету, выявились многочисленные проблемы, связанные с уязвимостью и незащищенностью мигрантов, как перед самим вирусом (их медицинское обеспечение в принимающих странах оставляет желать лучшего), так и перед государством, которое разрешило им приехать на работу или на учебу, но, введя различные ограничительные меры, зачастую просто оставило мигрантов без работы, а значит, и без средств к существованию, не обеспечило в должной мере пособиями и другой помощью и ограничило свободу перемещения мигрантов.

В этом плане трудно сказать, от чего мигранты пострадали более - от пандемии или от принимающего государства, которое в критический момент просто отвернулось от них, оставив без работы, без возможности вернуться на родину, без права на перемещение, по сути, практически без права на жизнь. Это существенно понижает уровень базиса социальной сплоченности мигрантов, а именно, доверие и равноправное партнерство в принимающем обществе, что способствует возникновению и развитию новых тенденций международных миграционных процессов, изучение которых является важной и актуальной исследовательской задачей.

Цель и предмет исследования. Целью настоящей статьи является выявление и анализ факторов и тенденций становления и развития социальной сплоченности мигрантов. Поскольку в результате повсеместной практики социального дистанцирования в условиях пандемии COVID-19 возникла тенденция перемещения социальных связей мигрантов из сферы «off-line» в сферу «on-line», то предметом анализа выступает проявление социальной сплоченности в мигрантских социальных сетях.

Авторская гипотеза. Согласно авторской гипотезе социальная сплоченность мигрантов формируется как дополнение этнической солидарности в условиях социальных трансформаций, вызванных глобальными изменениями, в том числе и вызванных пандемией COVID-1.
Социальная сплоченность мигрантов в условиях ограничения форм и возможностей их социальной адаптации и кризиса доверия к принимающему обществу и государству выступает как дополнение этнической сплоченности и как новая форма самоорганизации этнических мигрантских сообществ и наиболее зримо проявляется в мигрантских социальных сетях, становясь социальным мигрантским медиа.

Методология исследования. Методологией настоящего исследования являются системные методы оценки сообщений в мигрантских социальных сетях, становящихся мигрантскими социальными медиа, методы сетевого анализа, методы масс-медийных практик и мигрантской риторики в публичных материалах посредством выделения, сравнения, оценки и концептуализации тенденций трансформации миграционных процессов под действием глобальных изменений, в том числе и вызванных пандемией COVID-19, а также методы дискурсивного анализа мигрантского дискурса в аналитических материалах, представленные в работах таких отечественных исследователей, как Т.В. Батура, В. Д. Винник, Д. А. Губанов, М. Кастельс, С. Новикова, В.М. Сазанов, М. Ньюмэн и др., которые разрабатывают методы анализа социальных сетей, их характеристику как новую общественную сферу и форму организации общества и коммуникации в обществе [1-8].

Обсуждение. В современной исследовательской литературе нет общепринятого определения социальной сплоченности. Одним из первых обратился к анализу понятия социальной сплоченности Дж. Максвелл, который в 1996 году, характеризуя это понятие, включил в него создание общих ценностей и сообществ толкования, уменьшение различий в богатстве и доходах, это, как правило, дает людям ощущение того, что они заняты общим делом, сталкиваются с общими проблемами и являются членами одного сообщества [9]. В 1998 году Дж. Дженсон охарактеризовал «социально сплоченное общество» как общество, в котором все группы имеют чувство «принадлежности, участия, интеграции, признания и легитимности») 
[10]. В дальнейшем такие исследователи, как К. Бьюайс и тот же Дж. Дженсон показали, что понятие социальной сплоченности тесно связано с понятиями этнической солидарности, этнического и социального капитала и с понятием этнической идентичности [11]. Эти причинно-следственные связи в своих исследованиях продолжили Дж. Чэн и И. Чэн [12], а П. Бурдье уточнил, что социальную сплоченность институционализируют отношения взаимности и признания, партнерства и доверия [13].

Социальная сплоченность имеет огромное значение для динамической стабильности современного общества потому, что в основе социальной сплоченности находятся, прежде всего, права человека, без которых не обеспечиваются свобода и равенство. Мигранты в принимающем обществе вырабатывают свои ресурсы выживания, не последними из которых являются этнический и социальный капитал, в основе которых, как и в основе социальной солидарности, лежат доверие и равноправное партнерство. Но о каком доверии и равноправии может идти речь, если принимающее государство «по умолчанию» считает мигрантов людьми второго сорта? Тогда компенсаторным ресурсом выживания мигрантских общин становится так называемый этнический капитал, который в кризисных условиях противопоставляется социальному капиталу и может служить питательной почвой этнических протестов, межнациональных конфликтов и даже терроризма.

Совет Европы определил список основных приоритетов социальной сплоченности следующим образом: лояльность и солидарность; сила социальных отношений и общих ценностей; чувства общей идентичности и чувства принадлежности к одной общине; доверие между членами сообщества, сокращение неравенства и социальной изоляции [14].

В современной исследовательской литературе, как отмечает Б. Парех, социальная сплоченность мигрантов проистекает из таких основных ценностей, как равенство и справедливость, диалог и консультации, терпимость, компромисс и уступчивость, признание и уважение разнообразия; решимость противостоять расизму и ксенофобии [15].

Социальная сплоченность как понятие мигрантов является многогранным и каса- ется расширения культурного и этнического разнообразия, включает модели кооперативного социального взаимодействия, базовые социальные ценности, то, на чем они культивируются и чем поддерживаются, а также соглашения по взаимности претензий и обязательств [16].

Важнейшим фактором становления социальной сплоченности мигрантов является то, что она формируется изначально на основе этнической сплоченности, которая выражается в поддержании культурных связей диаспоры с исторической родиной, трансляции национальных новостных поводов, эмоциональной поддержке соотечественников, формировании религиозного этно-дискурса, формировании, продвижении и проявлении этнического капитала.

Этнический капитал мигрантов может быть как дополнением приобретаемого мигрантами социального капитала и этим способствовать успешной адаптации мигрантов, так и противостоящей альтернативой ему в той социальной ситуации, когда мигранты ощущают дефицит социального капитала, т. е. как отмечают отечественные исследователи И.М. Кузнецов и В.И. Мукомель, во многом связан с наличием этнических социальных сетей, которые облегчают их адаптацию [17].

Дефицит социального доверия у мигрантов по отношению к принимающему обществу и государству в условиях глобальных социальных изменений, связанных с пандемией, является триггером становления социальной сплоченности мигрантов. Рассмотрим факторы, способствующие тому, что в дополнение к этнической сплоченности в указанных условиях стала формироваться социальная сплоченность, а также выделим основные тенденции ее развития.

Как отмечалось выше, дефицит доверия возник в результате того, что социальное партнерство с принимающим государством в кризисной ситуации, которой является пандемия, явным образом является неравноправным. Отметим справедливости ради, что неравноправным оно было всегда и в любой стране (насколько цивилизованной она бы ни считалась), но в условиях глобального кризиса, вызванного пандемией, это стало настолько отчетливым, что сыграло роль своеобразного триггера трансформации миг- 
рационных процессов. Между тем, следует отметить, что этому способствовал целый ряд факторов.

Одним из таких факторов стало возникновение устойчивых ксенофобных настроений у населения принимающего общества в условиях пандемии COVID-19 [18]. Применительно к Российской Федерации нужно отметить, что до $70 \%$ россиян хотели бы ограничить проживание какой-либо этнической группы в России, $55 \%$ россиян согласны с лозунгом «Россия - для русских», свыше $30 \%$ - за то, чтобы сократить число мигрантов из Средней Азии, выходцев с Кавказа более $30 \%$, украинцев - около $20 \%$.

При этом $64 \%$ граждан считают, что их родственники могли бы выполнять работу, которой занимаются мигранты. Помимо высокой степени поддержки лозунга «Россия для русских», радикальные ксенофобы поддерживают ограничение притока трудовых мигрантов, а также одобряют дискриминационные объявления о сдаче жилья или о найме на работу по этническому или религиозному признаку, говорится в исследовании (результаты опроса показали массовое распространение таких объявлений; до $87 \%$ россиян заявили, что встречались с такими объявлениями) [19-21].

Важным индикатором роста ксенофобных настроений среди россиян является оценка вклада мигрантов в общественную жизнь. Так, по данным Н. Мастиковой, которая ссылается на информацию Европейского социального исследования (ESS), 60\% россиян негативно оценивают изменения, привносимые мигрантами в культуру, экономику и жизнь страны. Эти исследования также подтверждают корреляцию уровня жизни населения и уровень мигрантофобии: в странах с низким уровнем ВВП, низким уровнем жизни отношение к мигрантам будет хуже, чем в странах с высоким уровнем жизни и ВВП. Применительно к России следует отметить, что молодежь относится к мигрантам более радикально, а наиболее негативно относится к мигрантам группа 25-29-летних. Следует вывод: мы можем ожидать, что чем более нестабильна экономическая ситуация в стране, чем меньше уровень зарплат, тем больше коренные жители будут видеть угрозу, конкуренцию за рабочие места в мигрантах [22].
Одной из причин усиления ксенофобных настроений населения принимающего государства по отношению к мигрантам является ухудшение его материального положения. Применительно к РФ нужно отметить, что пандемия COVID-19 существенно ухудшила материальное положение некоторой части россиян. Так, во второй половине апреля до $42 \%$ выросла доля россиян, чье материальное положение ухудшилось. Серьезное снижение доходов отмечают 20\% граждан. Отмечается также, что свыше половины опрошенных жалуются на рост расходов, в частности, $33 \%$ назвали причиной повышения расходов рост цен, 9\% - необходимость тратить больше из-за того, что постоянно приходится находиться дома в период самоизоляции. Согласно апрельскому опросу об отказе от привычных товаров заявили $28 \%$ респондентов, а теперь об этом заявляют уже 44\% [23].

Немаловажным фактором в формировании социальной сплоченности является религиозный фактор. Дж. Предука прямо отмечает: «Нравственные традиции религии не раз доказывали свою пригодность в деле укрепления сообществ. Религия, удовлетворяя личные запросы индивидов, играет важную роль в поддержании социальной сплоченности» [24]. По мнению П. Брадата, религиозные традиции, будучи моральными, социальными и духовными основами повседневной жизни, как этнических общин, так и индивидов, являются основой формирования социального капитала, а, следовательно, и социальной сплоченности [25].

Кроме того, религиозные конгрегации побуждают людей поддерживать коммуникацию в общине, как отмечает Дж. Кольман [26], что способствует укреплению социальной сплоченности (это называется «бриджинговым социальным религиозным капиталом»).

При рассмотрении содержательного наполнения социальной солидарности мигрантов и факторов, способствующих возникновению и развитию этого нового качества миграционных процессов, необходимо акцентировать внимание на том, где, в чем и как проявляется социальная солидарность мигрантов.

Такой глобальный процесс социальных изменений, как пандемия COVID-19, способствовал повсеместной практике социаль- 
ного дистанцирования, соблюдения социальной дистанции и самоизоляции, возникла тенденция перемещения социальных связей мигрантов из сферы «off-line» в сферу «on-line», в соответствии с чем социальное взаимодействие мигрантских общин между собой и с принимающим обществом в значительной степени переместилось в сферу мигрантских социальных сетей. Согласно этому именно в социальных сетях и находит свое проявление социальная солидарность мигрантов.

Этнические социальные сети - это не только новые каналы коммуникации, они являются социально-информационным механизмом, который способствует формированию миграции, создают не только новую инфраструктуру, но и новую информационную культуру, способствуют развитию социальных отношений, являются богатым источником инсайдерских знаний о миграции, что делает их важным средством изучения миграционных процессов.

Солидаризация с членами этнического сообщества в этнических социальных сетях на основе форматов этнического капитала, как отмечают М.А. Панарина и И. А. Лавров, является базисом формирования идентичности [27]. Идентичность, формирующаяся в социальных сетях, зависит от следующих характеристик: раса, этнос, национальность, класс, пол и т.д., а также от их восприятия в принимающей стране, и хотя расовые, этнические и национальные категории объединяют людей в соответствующие общности, на этническую идентичность оказывают влияние такие характеристики, как образование, профессия, ценности, идентичность, культурный репертуар, социальная роль.

Исследователи отмечают, что там, где сложились наиболее продуктивные этнические социальные сети, уровень сплоченности, солидарности и взаимной поддержки мигрантов является самым высоким, что в условиях пандемии способствует взаимопомощи и партнерству. Новые социальные медиа способствуют лучшей информированности, а значит, и социальной защищенности мигрантов. Они также способствуют эффективному диалогу мигрантских сообществ с правительственными органами и гражданским обществом, а это и есть наиболее отчетливый показатель социальной сплоченности мигрантов. Социальные сети, такие как Facebook, Instagram, Twitter, предоставляют свои электронные платформы и создаваемое на них виртуальное пространство для коллективных обсуждений и переговоров как с другими этническими общинами, так и с политическими, социальными и гражданскими институтами принимающего государства и общества. Особенно это важно в условиях пандемии, когда люди в силу социального дистанцирования, самоизоляции, карантина и удаленной работы изолированы друг от друга.

В условиях пандемии COVID-19 в этнических социальных сетях мигрантов все более стали проявляться принципы транснационализма, и понятие солидарности стало наполняться не только этнонациональным, но и широким социальным содержанием, в частности, это выражается в правозащитной и гуманитарной направленности мигрантских настроений и действий.

Г. Филиз и А. Асад в своем материале «Сети мигрантов. Новые тенденции в социальных и поведенческих науках» утверждают, что так называемая «мигрантская риторика» в мигрантских социальных сетях наполняется социально значимой проблематикой, и это является новым трендов развития миграционных процессов [28].

Наряду с ростом расистских и ксенофобских настроений нарастает тенденция антирасистских мероприятий и кампаний, в том числе в этнических социальных сетях, на этнических форумах мигрантов, где размещаются сообщения антирасистской направленности, а также списки жертв расистских действий.

Проявляется еще одна тенденция, трансформирующая миграционные процессы, которая находит тоже свое отражение в социальных сетях. Данная тенденция связана c ранее сложившейся транснациональной мобильностью международных мигрантов. Так, в материалах, ставших публичными, немецкие аналитики А. Кнолль и А. Бизонг подчеркивают, что из-за кризиса, вызванного пандемией COVID-19, в результате закрытия национальных границ затормозилась и практически прекратилась транснациональная мобильность международных мигрантов, и следует ожидать, что в посткоронавирус- 
ном мире национальные государства изменят свою миграционную политику в направлении ограничения международной миграции и ужесточения требований к мигрантам [29].

Результаты. Концептуализация различных дискурсов позволила сформулировать понятие социальной сплоченности мигрантов как множество вертикальных и горизонтальных взаимодействий между членами мигрантского сообщества, которое включает в себя совокупность установок и норм, основанных на чувстве принадлежности к социуму сообщества, на доверии и готовности участвовать в делах сообщества, на отношении к другим сообществам и к принимающему обществу в целом.

Она имеет прямое отношение к таким базовым параметрам международных миграционных процессов, как этническая солидарность, этнический и социальный капитал, идентичность мигрантов. Изменение указанных параметров существенным образом конституирует и трансформирует понятие социальной сплоченности.

Обобщение исследовательских материалов и документы Совета Европы дали возможность выявить основные приоритеты социальной сплоченности мигрантов: лояльность и солидарность, сила социальных отношений и общих ценностей, чувство общей идентичности и чувство принадлежности к одной общине, доверие между членами сообщества, сокращение неравенства и социальной изоляции, в соответствии с чем социальная сплоченность мигрантов проистекает из таких основных ценностей, как равенство и справедливость, диалог и консультации, терпимость, компромисс и уступчивость, признание и уважение разнообразия и решимость противостоять расизму и ксенофобии.

Показано, что необходимо выявлять факторы социальной сплоченности мигрантов, обуславливающих ее формирование и развитие. Одним из важнейших факторов становления социальной сплоченности мигрантов является то, она формируется изначально на основе этнической сплоченности, которая выражается в поддержании культурных связей диаспоры с исторической родиной, трансляции национальных новостных поводов, эмоциональной поддержке соотечест- венников, формировании религиозного этнодискурса, формировании, продвижении и проявлении этнического капитала.

В условиях глобального кризиса, вызванного пандемией COVID-19, зафиксирован возникший дефицит социального доверия у мигрантов по отношению к принимающему обществу и государству, что стало триггером становления социальной сплоченности мигрантов.

К числу других факторов следует отнести возникновение устойчивых ксенофобных настроений у населения принимающего общества, учитывая, что причиной их усиления является ухудшение материального положения принимающего населения.

Немаловажным фактором в формировании социальной сплоченности является религиозный фактор, поскольку религия, удовлетворяя личные запросы индивидов, играет важную роль в поддержании социальной сплоченности, а религиозные конгрегации побуждают людей поддерживать коммуникацию в общине.

Отмечено, что поскольку в условиях глобальной пандемии возникла тенденция перемещения социальных связей мигрантов из сферы «off-line» в сферу «on-line», в соответствии с чем социальное взаимодействие мигрантских общин между собой и с принимающим обществом в значительной степени переместилось в сферу мигрантских социальных сетей. Согласно этому именно в социальных сетях и находит свое проявление социальная солидарность мигрантов.

Показано, что этнические социальные сети - это не только новые каналы коммуникации, они являются социально-информационным механизмом, который способствует формированию миграции, создают не только новую инфраструктуру, но и новую информационную культуру, способствуют развитию социальных отношений, являются богатым источником инсайдерских знаний о миграции, что делает их важным средством изучения миграционных процессов.

Выявлено становление социальной сплоченности мигрантов на разных этапах глобальных социальных изменений, чем в настоящее время явилась пандемия COVID-19. На раннем этапе контент социальных взаимодействий мигрантов характеризуется, прежде 
всего, солидаризацией мигрантских общин между собой и выражается в формировании этнического капитала, составляющего основу социальной адаптации мигрантов, которая является основой этнической идентичности.

Мигрантские социальные сети, облегчая социальную адаптацию мигрантов, являясь информационной базой этнической концентрации, выступают в роли новых медиа, способствуют лучшей социальной защищенности мигрантов. Они также помогают эффективному диалогу мигрантских сообществ с правительственными органами и гражданским обществом, а это и есть наиболее отчетливый показатель социальной сплоченности мигрантов, что нашло свое выражение в поддержке массового антирасистского движения-протеста, связанного с убийством полицейскими афроамериканца Флойда Мейвезера под лозунгом «Black Lives Matter».

В мигрантских социальных сетях на следующем этапе нашли свое отражение принципы не узкой этнической направленности, а информационного транснационализма, в связи с чем само понятие этнической мигрантской солидарности стало наполняться не только этнонациональным, но и широким социальным содержанием, в частности, это выражается в правозащитной и гуманитарной направленности мигрантских настроений и действий.

Эти мигрантские действия и настроения усилились в соответствии с ростом расистских и ксенофобских настроений в принимающем обществе, что выражается в нарастании тенденции антирасистских мероприятий и кампаний, в том числе в этнических социальных сетях, на этнических форумах мигрантов, где размещаются сообщения антирасистской направленности, а также списки жертв расистских действий, что явным образом конституирует контент социальной сплоченности мигрантов.

\section{Литература}

1. Батура Т.В. Методы анализа компьютерных социальных сетей [Электронный peсурс] // Вестник НГУ. - 2012. - Т. 10. Вып. 4. - С. 13-28. - Режим доступа: http:// lib.nsu.ru:8080/jspui/bitstream/nsu/250/1/02.pdf (Дата обращения: 24.07.13).
2. Винник В.Д. Социальные сети как феномен организации общества: сущность и подходы к использованию и мониторингу// Философия науки. - 2012. - №4 (55).

3. Губанов Д. А. Социальные сети: модели информационного воздействия, управления и противостояния / Д. А. Губанов, Д. А. Новиков, А.Г. Чхартишвили. - М.: Издательство физико-математической литературы, 2010. $228 \mathrm{c}$.

4. Зорин И. В. В социальных сетях / Издательский дом «Эксмо», 2014. - 352 с.

5. Новикова С. Блоги и социальные сети как пространство политических коммуникаций / Светлана Новикова. - M.: LAP Lambert Academic Publishing, 2018. - 124 p.

6. Кастельс М. Формирование общества сетевых структур // Новая постиндустриальная волна на Западе. Антология. - М.: Academia, 1999. - C. 494-505.

7. Сазанов В.M. Социальные сети как новая социальная сфера. Системный анализ и прогноз. - М.: Лаборатория СВМ, 2010. — $180 \mathrm{c}$.

8. Ньюман M. Сети: Введение. Oxford University Press, 2010. — 784 c.

9. Maxwell J. Social Dimensions of Economic Growth, Eric John Hanson Memorial Lecture Series. University of Alberta. - 1996. Vol. VIII.

10. Jenson J. Defining and Measuring Social Cohesion // Commonwealth Secretariat and United Nations Research Institute for Social Development. - 2010. - $34 \mathrm{p}$.

11. Beauvais C., Jenson J. Social Cohesion: Updating the State of Research, Canadian Policy, Research Networks, Canadian Heritage, Ottawa. - 2002.

12. Chan J., Chan E. Reconsidering Social Cohesion: Developing a Definition and Analytic Framework for Empirical Research // Social Indicators Research. — 2006. - Vol. 75. №2. $-290 \mathrm{p}$.

13. Бурдье П. Формы капитала / П. Бурдье // Экономическая социология. - Май, 2005. - T. 6. - №3. - C. 60-74.

14. Guerrie $S$. From the Hague Congress to the Council of Europe: Hopes, achievements and disappointments in the parliamentary way to European integration // Parliaments, Estates and Representation. - 2014. - Vol. 34. - №2. Pp. 216-227. 
15. Parekh B. The Future of Multi-Ethnic Britain, Runnymede Trust, London. - 2000.

16. The Southall Report: Cultural Diversity and Community Cohesion: Executive Summary, Swrt-Shrg Conference, Southall, Middlesex. 9 November 2002.

17. Кузнеиов И. М., Мукомель В.И. Адаптационные возможности и сетевые связи мигрантских этнических меньшинств. - М.: Ин-т социологии РАН, 2005. - $51 \mathrm{c}$.

18. Онлайн-конференция «Проявления расизма, ксенофобии и миграционные процессы в условиях пандемии коронавируса» [Электронный ресурс]. - Режим доступа: https:// www.asi.org.ru/event/2020/05/08/onlajnkonferen/ (Дата обращения: 12.05.2020).

19. Мигрантам здесь не место. Почему большинство россиян против приезжих [Электронный ресурс]. - Режим доступа: https://proexpedition.ru/layfhaki/migrantamzdes-ne-mesto-pochemu-bolshinstvo-rossiyanprotiv-priezzhih.html.

20. Онодэра Ю. Как россияне относятся к мигрантам [Электронный ресурс]. Режим доступа: https://www.the-village.ru/ village/city/news-city/362417-kak-rossiyaneotnosyatsya-k-migrantam (Дата обращения: 18.09.2019).

21. Расизм и ксенофобия [Электронный pecypc]. - Режим доступа: https://www. wonderzine.com/wonderzine/life/life/250653racism-and-xenophobia (Дата обращения: 18.06.2020).

22. Мастикова Н. Чтобы прекратить естественную убыль населения, России нужно полмиллиона мигрантов в год [Электронный ресурс]. - Режим доступа: https:// realnoevremya.ru/articles/166801-natalyamastikova-ob-otnoshenii-rossiyan-k-igrantam (Дата обращения: 22.02.2020).

23. Почти половина россиян заявили об ухудшении материального положения в период пандемии [Электронный ресурс]. - Режим доступа: https://newizv.ru/ news/society/07-05-2020/pochti-polovinarossiyan-zayavili-ob-uhudshenii-materialnogopolozheniya-v-period-pandemii (Дата обращения: 7.05.2020).

24. Preduca G. Democracy, Religious Ethics and Human Rights // Contemporary Readings in Law and Social Justice. - 2011. - Vol. 3. №1. - P. 129.
25. Bramadat P.A. Religion, Social Capital and «The Day that Changed the World»// Journal of International Migration and Integration. 2005. - Vol. 69. - №2. - P. 209.

26. Coleman J. Religious Social Capital: Its Nature, Social Location and Limits // Smith C. (Ed.). Religion as Social Capital: Producing the Common Good. Waco, TX: Baylor University Press, 2003. - P. 36.

27. Панарина М.А., Лавров И.А. Роль социальных сетей в формировании идентичности мигранта [Электронный ресурс]/ Цифровая социология. - 2019. - №2 (4). C. 25-30. - Режим доступа: https://doi. org/10.26425/2658-347X-2019-4-25-30.

28. Filiz G., Asad A.L. Migrant Networks. Emerging Trends in the Social and Behavioral Sciences: An Interdisciplinary, Searchable, and Linkable Resource: 1-13 [Electronic resource].URL: doi:10.1002/9781118900772.etrds0220.

29. Knoll A., Bisong A. Migration, mobility and COVID-19 [Electronic resource]. - URL: https://ecdpm.org/talking-points/migrationmobility-covid-19-tale-of-many-tales/ (Date accessed: 30.03.2020).

\section{References}

1. Batura T.V. Metody analiza komp'yuternykh sotsial'nykh setey [Methods of analysis of computer social networks] [Elektronnyy resurs] // Vestnik NSU. - 2012. - Vol. 10. Issue 4. - Pp. 13-28. - URL: http://lib.nsu. ru:8080/jspui/bitstream/nsu/250/1/02.pdf (Date accessed: 07.24.13).

2. Vinnik V.D. Sotsial'nyye seti kak fenomen organizatsii obshchestva: sushchnost' i podkhody $\mathrm{k}$ ispol'zovaniyu i monitoringu [Social networks as a phenomenon of the organization of society: the essence and approaches to the use and monitoring]// Filosofiya nauki [Philosophy of Science]. - 2012. - №4 (55).

3. Gubanov D.A. Sotsial'nyye seti: modeli informatsionnogo vozdeystviya, upravleniya i protivostoyaniya [Social networks: models of information influence, management and confrontation]/ D.A. Gubanov, D.A. Novikov, A.G. Chkhartishvili. - Moscow: Izdatel'stvo fiziko-matematicheskoy literatury, 2010. - 228p.

4. Zorin I. $V$. V social'nyh setjah [In social networks] / I. V. Zorin. - Moscow: Izdatel'stvo «Eksmo» LLC, 2014. - 352p. 
5. Novikova S. Blogi i sotsial'nyye seti kak prostranstvo politicheskikh kommunikatsiy [Blogs and social networks as a space of political communications] / Svetlana Novikova. Moscow: LAP Lambert Academic Publishing, 2018. - $124 \mathrm{p}$.

6. Castells M. Formirovaniye obshchestva setevykh struktur [Formation of a society of network structures] // Novaya postindustrial'naya volna na Zapade. Antologiya. [New postindustrial wave in the West. Anthology]. - Moscow: Academia, 1999. - Pp. 494-505.

7. Sazanov V.M. Sotsial'nyye seti kak novaya sotsial'naya sfera. Sistemnyy analiz i prognoz [Social networks as a new social sphere. System analysis and forecast]. - Moscow: Laboratoriya SVM, 2010. - $180 \mathrm{p}$.

8. Newman M. Networks: An Introduction. Oxford University Press, 2010. — 784 p.

9. Maxwell J. Social Dimensions of Economic Growth, Eric John Hanson Memorial Lecture Series. University of Alberta. — 1996. Vol. VIII.

10. Jenson J. Defining and Measuring Social Cohesion // Commonwealth Secretariat and United Nations Research Institute for Social Development. - 2010. - $34 \mathrm{p}$.

11. Beauvais C., Jenson J. Social Cohesion: Updating the State of Research, Canadian Policy, Research Networks, Canadian Heritage, Ottawa. - 2002.

12. Chan J., Chan E. Reconsidering Social Cohesion: Developing a Definition and Analytic Framework for Empirical Research // Social Indicators Research. - 2006. - Vol. 75. №2. - P. 290.

13. Bourdieu P. Formy kapitala [Forms of capital] / P. Bourdieu// Jekonomicheskaja sociologija [Economic sociology]. — May, 2005. Vol. 6. - №3. - Pp. 60-74.

14. Guerrie $S$. From the Hague Congress to the Council of Europe: Hopes, achievements and disappointments in the parliamentary way to European integration // Parliaments, Estates and Representation. - 2014. - Vol. 34. - №2. Pp. 216-227.

15. Parekh B. The Future of Multi-Ethnic Britain, Runnymede Trust, London. - 2000.

16. The Southall Report: Cultural Diversity and Community Cohesion: Executive Summary, Swrt-Shrg Conference, Southall, Middlesex, 9 November 2002.
17. Kuznetsov I.M., Mukomel V.I. Adaptatsionnyye vozmozhnosti i setevyye svyazi migrantskikh etnicheskikh men'shinstv [Adaptation opportunities and networking of migrant ethnic minorities]. - Moscow: In-t sotsiologii RAN, 2005. - 51 p.

18. Onlayn-konferentsiya «Proyavleniya rasizma, ksenofobii i migratsionnyye protsessy $\mathrm{v}$ usloviyakh pandemii koronavirusa» [Online conference «Manifestations of racism, xenophobia and migration processes in the context of the coronavirus pandemic»)] [Electronic resource]. - URL: https://www.asi.org.ru/ event/2020/05/08/onlajnkonferen/ (Date accessed: 12.05 .2020$)$.

19. Migrantam zdes' ne mesto. Pochemu bol'shinstvo rossiyan protiv priyezzhikh [Migrants do not belong here. Why are most Russians against visitors] [Elektronnyy resurs]. — URL: https://proexpedition.ru/layfhaki/migrantamzdes-ne-mesto-pochemu-bolshinstvo-rossiyanprotiv-priezzhih.html.

20. Onodera Yu. Kak rossiyane otnosyatsya $\mathrm{k}$ migrantam [How Russians relate to migrants] [Elektronnyy resurs]. — URL: https://www.thevillage.ru/village/city/news-city/362417-kakrossiyane-otnosyatsya-k-migrantam (Date accessed: 18.09.2019).

21. Rasizm i ksenofobiya [Racism and xenophobia] [Elektronnyy resurs]. — URL: https://www.wonderzine.com/wonderzine/life/ life/250653-racism-and-xenophobia (Date accessed: 18.06.2020).

22. Mastikova N. Chtoby prekratit' yestestvennuyu ubyl' naseleniya, Rossii nuzhno polmilliona migrantov $\mathrm{v}$ god [To stop the natural population decline, Russia needs half a million migrants a year] [Elektronnyy resurs]. — URL: https://realnoevremya.ru/articles/166801-natalyamastikova-ob-otnoshenii-rossiyan-k-igrantam (Date accessed: 22.02.2020).

23. Pochti polovina rossiyan zayavili ob ukhudshenii material'nogo polozheniya v period pandemii [Almost half of Russians announced a deterioration in their financial situation during a pandemic] [Elektronnyy resurs]. - URL: https://newizv.ru/news/society/07-05-2020/pochti-polovina-rossiyan-zayavili-ob-uhudsheniimaterialnogo-polozheniya-v-period-pandemii (Date accessed: 07.05.2020).

24. Preduca G. Democracy, Religious Ethics, and Human Rights // Contemporary Read- 
ings in Law and Social Justice. — 2011. Vol.3. - №1. - P. 129.

25. Bramadat P.A. Religion, Social Capital and «The Day that Changed the World» // Journal of International Migration and Integration. - 2005. - Vol. 69. - №2. - P. 209.

26. Coleman J. Religious Social Capital: Its Nature, Social Location and Limits // Smith C. (Ed.). Religion as Social Capital: Producing the Common Good. Waco, TX: Baylor University Press, 2003. - P. 36.

27. Panarina M.A., Lavrov I.A. Rol' sotsial'nykh setey $\mathrm{v}$ formirovanii identichnosti migranta [The role of social networks in the formation of migrant identity] [Elektronnyy resurs]// Tsifrovaya sotsiologiya [Digital Sociology]. 2019. - Vol. 2 (4). - Pp. 25-30. - URL: https://doi.org/10.26425/2658-347X-2019-4-25-30.

28. Filiz G., Asad A.L. Migrant Networks. Emerging Trends in the Social and Behavioral Sciences: An Interdisciplinary, Searchable, and Linkable Resource: 1-13. [Electronic resource]. URL: doi:10.1002/9781118900772.etrds0220.

29. Knoll A., Bisong A. Migration, mobility and COVID-19 [Electronic resource]. - URL: https://ecdpm.org/talking-points/migration-mobility-covid-19-tale-of-many-tales/ (Date accessed: 30.03.2020).

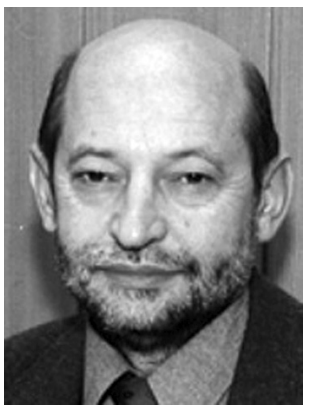

Курбатов Владимир Иванович - доктор философских наук, профессор, главный научный сотрудник Южно-Российского филиала Федерального научно-исследовательского Социологического центра Российской Академии наук. Область научных интересов: логика и методология социального познания, социальное проектирование и прогнозирование, социология коммуникации, социальная коммуникация в информационном обществе. Автор более 100 научных публикаций, в том числе 5 с грифом Министерства. Общий стаж работы в отрасли высшего образования - более 30 лет.

Kurbatov Vladimir Ivanovich - Doctor of Philosophical Sciences, Professor, Chief Researcher of the South Russian Branch of the Federal Center of Theoretical and Applied Sociology of the Russian Academy of Sciences. Research interests: logic and methodology of social cognition, social design and forecasting, sociology of communication, social communication in the information society. Author of more than 100 scientific publications, including 5 with the stamp of the Ministry. Total work experience in the field of higher education is more than 30 years.

344006, г. Ростов-на-Дону, ул. Пушкинская, 160 160 Pushkinskaya st., 344006, Rostov-on-Don, Russia E-mail: kurbashy@list.ru 


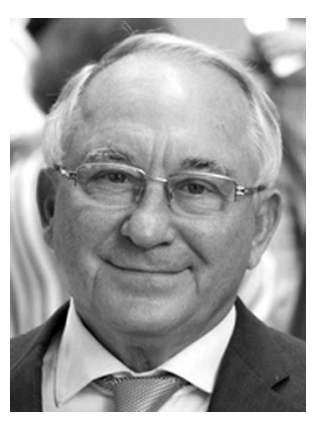

Волков Юрий Григорьевич - Заслуженный деятель науки РФ, доктор философских наук, профессор, заведующий кафедрой теоретической социологии и методологии региональных исследований ИСиР ЮФУ. Научный руководитель ЮжноРоссийского филиала Федерального научно-исследовательского социологического центра Российской академии наук (ЮРФ ФНИСЦ РАН). Действительный член Российской академии социальных наук, действительный член Нью-Йоркской академии наук (1995). Специалист в области исследований социологии креативности и креативного класса в российской социологической науке, социальной имитации, гуманистической идеологии, формирования идентичности. Основатель и руководитель научной школы «Многоуровневая идентичность и идеология инновационного развития российского общества». Лауреат премии им. И.Г. Петровского, награжден серебряной медалью им. П. Сорокина за вклад в развитие социологии в России, серебряной медалью им. П. Сорокина за вклад в науку, серебряной медалью «Джим Торосян». Общий стаж научно-педагогической работы составляет более 50 лет.

Volkov Yury Grigoryevich - Honored scientist of the Russian Federation, Doctor of Philological Sciences, Professor, Head of the Department of Theoretical Sociology and Methodology of Regional Studies of the Institute of Sociology and Regional Studies of the Southern Federal University. Scientific Supervisor of the South Russian Branch of Science of the Federal Center of Theoretical and Applied Sociology of the Russian Academy of Sciences. Member of the Russian Academy of Social Sciences, Member of the New York Academy of Sciences (1995). Specialist in the field of research on the sociology of creativity and the creative class in Russian sociological science, social imitation, humanistic ideology, identity formation. Founder and head of the scientific school «Multilevel identity and ideology of innovative development of Russian society». I. G. Petrovsky prizewinner, was awarded P. Sorokin silver medal for his contribution to the development of sociology in Russia, P. Sorokin silver medal for his contribution to science, «Jim Torosyan» silver medal. The general experience of scientific and pedagogical work is more than 50 years.

344006, г. Ростов-на-Дону, ул. Пушкинская, 160

160 Pushkinskaya st., 344006, Rostov-on-Don, Russia

E-mail: ugvolkov@sfedu.ru 